\begin{tabular}{|c|c|c|c|c|}
\hline Submission & Review Process & Revised & Accepted & Published \\
\hline $31-11-2019$ & $31-11 \mathrm{~s} / \mathrm{d} 26-12-2019$ & $25-12-2019$ & $30-12-2019$ & $25-01-2020$ \\
\hline
\end{tabular}

Ampera: A Research Journal on Politics and

Islamic Civilization, Vol. 1 No. 1, Januari 2020 (14-23)

Published by: Politik Islam Universitas Islam Negeri Raden Fatah Palembang

\title{
Political Marketing dalam Pemilihan Gubernur Sumatera Selatan Tahun 2018 (Studi Kasus Tim Pemenangan Herman Deru-Mawardi Yahya di Kota Palembang)
}

\author{
Anggi Septiyanti \\ Program Studi Politik Islam Universitas Islam Negeri Raden Fatah Palembang \\ anggiseptiyanti169@gmail.com \\ Syawaluddin \\ Program Studi Politik Islam Universitas Islam Negeri Raden Fatah Palembang \\ syawalibrahim71@gmail.com \\ Nico Oktario Adytyas \\ Program Studi Politik Islam Universitas Islam Negeri Raden Fatah Palembang \\ Nadytyas@gmail.com
}

\begin{abstract}
The title of this research is "Political Marketing in Pilkada (Case Study: Victory of the Herman Deru-Mawardi Yahya Pair in the Election of the Governor of South Sumatra 2018 in the City of Palembang)". This study examines the phenomenon of political marketing as a strategy in a campaign. This paper elaborates and discusses how the political marketing process carried out by the successful team of the couple Herman Deru-Mawardi Yahya in Palembang City. The findings obtained from this study indicate that the political marketing process carried out by the success team of Herman Deru-Mawardi Yahya in Palembang City was very structured and managed to get the voice of the people of Palembang City. The political marketing process carried out by the success team of Herman Deru-Mawardi Yahya in the city of Palembang is first, showing the political products of this couple to the community such as spreading the vision and mission program of this couple to the entire Palembang City community. Secondly, to promote the people of Palembang City both through direct interaction and through print media, electronic media, and social media carried out directly by successful teams. Third, determine prices in the campaign, both in the campaign funding process and to build the price of the image of the couple. Fourth, the location of the campaign which was not only focused on one place but spread throughout the corner of the city of Palembang, because there was no major campaign in the city of Palembang.
\end{abstract}

Keywords: political marketing, success team, palembang city 


\begin{abstract}
Abstrak
Judul penelitian ini adalah "Pemasaran Politik di Pilkada (Studi Kasus: Kemenangan Pasangan Herman Deru-Mawardi Yahya dalam Pemilihan Gubernur Sumatera Selatan 2018 di Kota Palembang)". Studi ini meneliti fenomena pemasaran politik sebagai strategi dalam kampanye. Penelitian ini menguraikan dan membahas bagaimana proses pemasaran politik dilakukan oleh tim sukses pasangan Herman Deru-Mawardi Yahya di Kota Palembang. Temuan yang diperoleh dari penelitian ini menunjukkan bahwa proses pemasaran politik yang dilakukan oleh tim sukses Herman Deru-Mawardi Yahya di Kota Palembang sangat terstruktur dan berhasil mendapatkan suara masyarakat Kota Palembang. Proses pemasaran politik yang dilakukan oleh tim sukses Herman Deru-Mawardi Yahya di kota Palembang adalah yang pertama, menunjukkan produk politik pasangan ini kepada masyarakat seperti menyebarkan visi dan program misi pasangan ini ke seluruh Kota Palembang masyarakat. Kedua, untuk mempromosikan masyarakat Kota Palembang baik melalui interaksi langsung dan melalui media cetak, media elektronik, dan media sosial yang dilakukan langsung oleh tim yang sukses. Ketiga, tentukan harga dalam kampanye, baik dalam proses pendanaan kampanye dan untuk membangun harga citra pasangan. Keempat, lokasi kampanye yang tidak hanya terfokus pada satu tempat tetapi tersebar di seluruh sudut kota Palembang, karena tidak ada kampanye besar di kota Palembang.
\end{abstract}

Keywords: pemasaran politik, tim sukses, kota palembang

\title{
PENDAHULUAN
}

Penelitian ini akan mengkaji bagaimana strategi pemasaran politik dari pasangan gubernur Herman Deru-Mawardi Yahya untuk menarik suara masyarakat. Penelitian ini penting untuk dilakukan agar kita dapat mengetahui lebih dalam lagi strategi apa yang digunakan oleh pasangan calon gubernur tersebut untuk menarik suara masyarakat terkhusunya suara masyarakat Kota Palembang. Faktor yang menarik dari penilitian ini juga adalah untuk mengetahui langkah-langkah apa saja yang diambil oleh pasangan Herman Deru dan Mawardi Yahya dalam melawan dinasti petahana atau representasi dari Alex Noerdin (gubernur periode 2013-2018) yang mengusung dan memajukan anaknya untuk ikut dalam kontestasi pilkada di tahun 2018, padahal seperti yang kita ketahui Herman Deru pernah maju juga pada tahun 2013 dan bersaing dengan Alex Noerdin tetapi ia kalah oleh Alex Noerdin.

Hal yang menarik lainnya adalah apakah ada strategi khusus yang digunakan Herman Deru pada pilkada di tahun 2018 ini. Secara garis besar dapat dikatakan bahwa Herman Deru dapat melawan dinasti petahana dan partai yang telah mapan, sehingga bisa mengalahkan pasangan yang lebih kuat. Pemilihan kepala daerah (Pilkada atau Pemilukada) dilakukan secara langsung oleh penduduk daerah administratif setempat yang memenuhi syarat. Pemilihan kepala daerah dilakukan satu paket bersama dengan wakil kepala daerah. Sebelum tahun 2005, kepala daerah dan wakil kepala daerah dipilih oleh Dewan Perwakilan Rakyat Daerah (DPRD). Sejak berlakunya Undang-Undang Nomor 32 Tahun 2004 tentang Pemerintahan Daerah, kepala daerah dipilih secara 
langsung oleh rakyat melalui Pemilihan Kepala Daerah dan Wakil Kepala Daerah atau disingkat Pilkada. Pilkada pertama sekali dilakukan pada bulan Juni 2005. Sejak berlakunya Undang-Undang Nomor 22 Tahun 2007 tentang penyelenggaraan Pemilihan Umum, pilkada dimasukkan dalam rezim pemilu, sehingga secara resmi bernama Pemilihan Umum Kepala Daerah dan Wakil Kepala Daerah atau disingkat Pemilukada. Pemilihan kepala daerah pertama yang diselenggarakan berdasarkan undang-undang ini adalah Pilkada DKI Jakarta 2007.

Disahkannya undang-undang tersebut maka rakyat secara langsung memiliki hak untuk memilih pasangan mana yang mereka inginkan. Untuk menentukan pilihannya, rakyat tentulah harus mengetahui siapa saja yang mencalonkan diri dalam pemilukada nantinya. Tak hanya itu rakyat yang akan memilih juga perlu untuk mengetahui visi misi dari pasangan calon yang akan maju. Mengetahui visi dan misi dari pasangan calon diperlukan guna untuk mengetahui hal apa saja yang akan dilakukan pasangan calon jika menang dalam pilkada nantinya. Bagi pasangan calon yang akan maju dalam pilkada juga harus mengetahui hal apa saja yang diperlukan oleh masyarakat luas, ini dilakukan agar terjadi kesesuain anatara visi misi pasangan calon dengan kebutuhan masyarakat.

Untuk mengetahui kebutuhan masyarakat perlu dilakukan survei guna benar-benar tahu apa yang dibutuhkan oleh masyarakat sehingga program-program yang diusung nantinya dapat berjalan sesuai dengan apa yang diperlukan dan akan menjadi tepat sasaran. Survei kebutuhan masyarakat dirasa sangat harus karena dengan cara mengetahui keinginan masyarakat tentu nantinya pasangan calon akan mendapat suara lebih banyak, karena dianggap masyarakat mampu untuk memenuhi kebutuhan mereka baik dalam bidang ekonomi maupun insprastruktur. Dan untuk menyebarkan visi misi pasangan calon adalah bagian dari political marketing yang digunakan oleh pasangan yang akan maju dalam pilkada. Political marketing adalah cara ataupun strategi yang digunakan oleh pasangan calon untuk meraih dan mendapatkan suara sebanyak-banyaknya.

Political marketing ini sangat penting untuk diterapkan karena dengan cara ini maka kandidat maupun masyarakat dapat memahami antara satu sama lain. Kandidat yang akan mencalonkan diri dalam pemilu harus mampu memahami sikap dan kebutuhan masyarakat, karena hal inilah yang jadi penilaian awal masyarakat untuk pasangan calon tersebut. Dengan cara memahami langsung kebutuhan masyarakat maka dapat dipastikan bahwa pasangan calon tersebut akan mendapatkan suara yang cukup banyak dari masyarakat. Dapat diartikan pula bahwa marketing politik merupakan sebuah alat atau metode bagi partai politik untuk melakukan kepada publik. Melalui marketing politik informasi mengenai partai politik lebih mudah didistribusikan kepada publik sehingga terjadi feed back atau hubungan timbal balik antara partai politik dan masyarakat. Adanya interaksi antara partai politik dan masyarakat memberikan pembelajaraan politik kepada masyarkat sehingga proses demokrasi terjadi. Di Indonesia penerapan marketing politik secara terbuka sejak 1998. Pada masa yang dikenal reformasi ini banyak partai yang bermunculan mencapai 150 partai. Namun, partai yang lolos pemilu 1999 hanya 48 partai. Selanjutnya pada pemilu 2004, jumlah partai politik yang ikut pemilu menyusut setengah dari jumlah sebelumnya, yaitu sebanyak 24 partai. Penyusutan ini tidak terlepas dari strategi masing- 
masing partai untuk mempertahankan dan mengembangkan partai politik dimasyarakat. Di sinilah marketing politik bermain. ${ }^{1}$

\section{METODE PENELITIAN}

Penelitian ini adalah penelitian kualitatif dengan pendekatan studi kasus. Dengan menggunakan pendekatan penelitian kualitatif dimana penelitian kualitatif sebagai metode ilmiah sering digunakan dan dilakasanakan oleh sekelompok peneliti dalam bidang ilmu sosial, beberapa alasan dikemukakan yang intinya bahwa penelitian kualitatif memperkaya hasil penelitian kualitatif. Penelitian kualitatif dilaksanakan untuk membangun pengetahuan melalui pemahaman dan penemuan. Pendekatan penelitian kualitatif adalah suatu proses penelitian pemahaman yang berdasarkanpada metode yang menyelidiki suatu fenomena sosial dan masalah manusia.

Peneliti mendeskripsikan suatu fenomena dengan berdasarkan pada pengalaman partisipan riset serta hasil observasi yang mendalam. Selain menggunakan observasi pada saat mengumpulkan data, cara lain yang digunakan oleh peneliti adalah wawancara. Cara mengolah data metode deskriptif, data yang telah terhimpun akan diolah kemudian dianalisis dengan menggunakan narasi tertentu yang diambil dari data di lapangan.

\section{HASIL DAN PEMBAHASAN}

Marketing politik merupakan aktivitas yang dilakukan oleh partai politik dan kontestan individu dalam merancang isu-isu yang akan dilempar ke masyarakat, mengkomunikasikan solusi yang hendak diterapkan ketika berkuasa, ideologi dan kontrol sosial partai/individu yang berkuasa. Marketing politik juga dapat berperan sebagai agen serta media perubahan hubungan dan interaksi politik. Marketing politik berperan dalam mengubah sistem politik yang tadinya dingin menjadi lebih hangat melalui pelibatan media dalam aktivitas politik.

Marketing politik menyediakan perangkat teknik dan metode marketing dalam dunia politik. Scammell, menyebutkan bahwa kontribusi marketing dalam dunia politik terletak pada strategi untuk dapat memahami dan menganalisis apa yang diinginkan dan dibutuhkan para pemilih. Aktivitas politik harus sesuai dengan aspirasi masyarakat luas. Mungkin sudah saatnya kita menyakini sudah berakhirnya mekanisme politik yang mencanangkan isu serta pesan politik secara top-down dari elit politik ke masyarakat. Masyarakat dewasa ini, seiring dengan berkembangnya masyarakat madani (civil society), adalah masyarakat yang semakin sadar akan hak dan kewajiban politik mereka. Selain itu, seiring dengan semakin mengakarnya budaya konsumerisme, masyarakat pun menjadi semakin pragmatis dalam menyikapi hal-hal yang berlangsung didunia politik. Yang secara khusus harus mereka perhatikan adalah apa yang dapat dilakukan oleh suatu partai atau kontestan untuk mengentaskan permasalahan yang sedang mereka hadapi. Bagi mereka, dunia politik bukan semata-mata merupakan permasalahan ideologi. Politik

\footnotetext{
${ }^{1}$ Aziz Nyimas, Peran Marketing Dalam Dunia Politik, Yayasan Obor Indonesia, April 2007, $x x i+357$ hlm.
} 
harus membumi serta selalu mencari jalan keluar bagi permasalahan bangsa dan negara.Janji politik saja dirasa semakin tidak memadai. Masyarakat semakin menuntut realisasi janji politik yang telah diberikan selama periode kampanye. ${ }^{2}$

Setiap pasangan atau calon yang akan maju dalam pilkada atau pemilu harus memiliki strategi yang tepat, agar dapat bersaing dengan pasangan atau calon lainnya. Persaingan politik merupakan "kodrat alamiah" yang harus ditempuh untuk mencapai kekuasaan dan kemenangan. Karena pemenangnya hanya satu individu atau kelompok sangat wajar bila masing-masing pihak berlomba-lomba untuk menjadi juara. Kompetisi politik akan berakhir dengan munculnya dukungan luas terhadap perjuangan suatu kelompok politik atau individu. ${ }^{3}$

Dengan semakin meningkatnya iklim persaingan yang sehat dan terbuka diantara partaipartai politik, banyak kalangan yang menganjurkan agar partai politik lebih berorientasi pasar. ${ }^{7}$ Tentunya konsep agar dunia politik berorientasi pasar bukan berarti sebuah partai politik atau seorang kandidat presiden harus at all cost memenuhi apa saja keinginan pasar. Karena masingmasing partai politik memiliki konfigurasi ideologi dan aliran pemikiran yang menjadikan satu partai berbeda identitas dengan partai lainnya. ${ }^{4}$

Marketing politik berbeda dengan marketing komersial. Marketing politik bukanlah konsep untuk menjual partai politik atau kandidat presidensial kepemilih, namun sebuah konsep yang menawarkan bagaimana sebuah partai politik atau kontestan bisa membuat program yang berhubungan dengan permasalahan aktual. Mencari, mengumpulkan, dan menganalisis informasi yang berasal dari masyarakat adalah hal penting yang harus dilakuakan sebelum menyusun program kerja. Setelah program kerja selesai disusun, cara mengemas dan mengkomunikasikannya juga merupakan peranan ilmu marketing yang sangat penting dalam politik. Marketing politik adalah konsep permanen yang harus dilakukan terus-menerus oleh sebuah partai politik atau kontestan dalam membangun kepercayaan dan image publik. ${ }^{5}$ Membangun kepercayaan dan image ini hanya bisa dilakukan melalui hubungan jangka panjang, tidak hanya pada massa kampanye. ${ }^{6}$

Dalam hal strategi komunikasi politik, marketing mengajarkan bagaimana partai politik bisa mendiferensiasikan produk dan image politiknya. Dengan begitu, masyarakat luas akan dapat mengenali identitas masing-masing partai politik dan kontestan perorangan. Karakteristik dan konten marketing politik berbeda dengan marketing komersial. Meskipun proses marketing politik

\footnotetext{
${ }^{2}$ Scammell dalam Firmanzah, Marketing Politik: Antara Pemahaman dan Realitas (Jakarta, Yayasan Obor

${ }^{3}$ Firmanzah, Mengelola Partai Politik:Komunikasi dan Positioning Ideologi Politikdi Era Demokrasi, (Jakarta, Yayasan Obor Indonesia: 2007), h. 125.

${ }^{4}$ O'Cass, Likker dan Negire dalam Firmanzah, Marketing Politik: Antara Pemahaman dan Realitas (Jakarta, Yayasan Obor Indonesia, 2012), h.197

${ }^{5}$ Butler dan Collins dalam Firmanzah, Marketing Politik: Antara Pemahaman dan Realitas (Jakarta, Yayasan Obor Indonesia, 2012), h.198

${ }^{6}$ Chandra, A., Darmawan, E., \& Yesi, Y. (2018). Upaya Komisi Pemilihan Umum Provinsi Sumatera Selatan dalam Meningkatkan Partisipasi Pemilih pada Pilkada Serentak 2018 dan Pemilu Serentak 2019. Jurnal Studi Sosial Dan Politik, 2(1), 12-30. https://doi.org/https://doi.org/10.19109/jssp.v2i1.4061
} 
Anggi Septiyanti,Syawaludin, Nico Oktario Adytyas, Political Marketing dalam Pemilihan Gubernur Sumatera Selatan (Studi Kasus Tim Pemenangan Herman Deru-Mawardi Yahya di Kota Palembang, Ampera: A Research Journal on

Politics and Islamic Civilization, Vol. 1 No.1, Januari 2020

masih mengikuti proses yang terdapat dalam marketing komersial, namun hal-hal yang dibahas tiap tahapan proses sangat berbeda antara marketing komersial dengan politik. ${ }^{7}$

\section{Strategi Politik Tim Sukses HDMY Kota Palembang Dalam Pilgub Sumsel 2018}

Peta persaingan politik yang semakin ketat mendorong Herman Deru-Mawardi Yahya dan tim suksesnya bekerja keras menarik hati para pemilihnya. Proses pendekatan marketing politik menjadi pilihan Herman Deru-Mawardi Yahya dan tim suksesnya dalam menghadapi pemilihan kepala daerah (Pilkada). ${ }^{8}$ Herman Deru-Mawardi Yahya adalah pasangan yang bukan terbilang baru dalam dunia politik mereka berdua merupakan mantan Bupati di daerah yang berbeda, Herman Deru adalah Bupati OKU Timur sedangkan Mawardi Yahya adalah Bupati Ogan Ilir. Tak perlu diragukan lagi bahwa strategi politik marketing pasangan tersebut akan sangat menarik hati pemilih.

Untuk mencapai sebuah kemenangan tidak bisa dilakukan melalui proses instan. Banyak hal yang harus dilalui, tim sukses atau tim pemenangan adalah tim yang harus memperjuangkan penuh kemenangan pasangan yang didukungnya. Berbeda dengan tim relawan tim sukses mempunyai tanggunjawab yang besar untuk memenangkan kandidat pasangan yang didukungnya. Tim sukses Herman Deru-Mawardi Yahya di Kota Palembang, mencoba menarik suara masyarakat Kota Palembang dengan cara memperkenalkan dan menunjukan visi misi dan program kerja unnggulan dari pasangan Herman Deru-Mawardi Yahya, ini dilakukan karena tim sukses di Kota Palembang tidak melakukan kampanye akbar seperti yang dilakukan oleh tim sukses di kabupaten dan kota lain yang ada di Sumatera Selatan. Masyarakat yang telah mengetahui visi misi dan program kerja tersebut akan secara otomatis memilih pasangan ini jika visi misi yang ditunjukan atau diperlihatkan cocok dengan apa yang mereka butuhkan.

Promosi dan penyebaran visi misi serta program kerja ini tidak hanya dilakukakan dengan satu cara seperti hanya terfokus pada kampanye saja. Karena tidak adanya kampanye akbar untuk menarik suara masa secara langsung, tim sukses Kota Palembang mengambil banyak cara untuk memperkenalkan pasangan Herman Deru-Mawardi Yahya beserta visi misi dan program kerjannya. Memanfaatkan media sosial adalah salah satu cara yang digunakan oleh tim sukses Herman Deru-Mawardi Yahya mengingat bahwa Kota Palembanng adalah kota dengan tingkat kemajuan teknologi yang baik dibandingkan kabupaten atau kota lain yang ada di Sumatera Selatan. Penggunaan media sosial sebagai salah satu media kampanye juga bertujuan untuk menarik suara kaum milenial Kota Palembang, karena kebanyak pengguna aktif media sosial adalah mereka yang berasal dari kalangan muda yang mungkin saja baru pertama kali akan menggunakan hak pilihnya. Pendanaan dalam proses kampanye sepenuhnya sudah diberikan oleh pasangan calon kepada tim sukses, dengan berbagai nominal yang berbeda-beda sesuai dengan bentuk kampanye yang dilakukan. Latar belakang pasangan juga menjadi perhatian dari

\footnotetext{
${ }^{7}$ Syukri, A., \& Meilandi, R. (\&nbsp;). Strategi Partai Koalisi dalam Pemenangan AW Nofiadi Mawardi - Ilyas Panji Alam pada Pemilihan Kepala Daerah Kabupaten Ogan Ilir Tahun 2015. Jurnal Studi Sosial Dan Politik, 2(1), 3143. https://doi.org/https://doi.org/10.19109/jssp.v2i1.4062

${ }^{8}$ Apriani, R., \& Maharani, M. (2019). Strategi Pemenangan Pasangan Calon Herman Deru Dan Mawardi Yahya Pada Pilkada Sumatera Selatan Tahun 2018. Jurnal Studi Sosial Dan Politik, 3(1), 17-27. https://doi.org/https://doi.org/10.19109/jssp.v3i1.4065
} 
masyarakat yang akan memilih, mengingat apakah pasangan tersebut memiliki latar belakang suku atau agama yang sama. Membangun image pasangan juga merupakan hal yang penting yang perlu dilakukan oleh tim sukses seperti memperlihatkan prestasi, kinerja dan kewibawaan dari pasangan calon. Penentuan tempat kampanye juga menjadi fokus awal yang harus ditentukan oleh tim sukses. Penentuan tempat kampanye ini bertujuan agar kampanye dapat langsung tersampaikan dan juga agar mendapatkan hasil yang maksimal.

Apa yang dilakukan oleh tim sukses Herman Deru-Mawardi Yahya di Kota Palembanng sesuai dengan teori dari Niffenigger yaitu teori 4P. Melalui program 4P tersebut terdiri dari Produk, Promosi, Price (Harga) dan Place (Tempat) tim sukses Herman Deru-Mawardi Yahya di Kota Palembang berusaha mencari suara pemilih terbanyak. Berikut ini, adalah langkah-langkah atau proses marketing politik yang dilakukan Herman Deru-Mawardi Yahya dan tim suksesnya di Kota Palembang.

\section{Produk Politik}

Dalam istilah pemasaraan kita mengenal, apabila perusahaan telah memutuskan segmen pasar mana yang dimasuki, perusahaan harus memutuskan bagaimana mendiferensiasikan penawaran pasarnya untuk setiap segmen sasaran dan posisi apa yang ingin ditempatinya dalam segmen tersebut. Posisi produk adalah tempat yang diduduki produk relatif terhadap pesaingnya dalam pikiran konsumen.Pemasar ingin mengembangkan posisi pasar unik bagi produk mereka. Jika sebuah produk dianggap sama persis dengan produk lainnya dipasar, konsumen tidak mempunyai alasan untuk membelinya ${ }^{9}$

Hal yang dibangun HDMY dan tim sukses di Kota Palembang adalah meyakinkan masyarakat akan visi misi pasangan tersebut. Memberikan harapan baru terhadap apa yang menjadi masalah di Kota Palembang seperti visinya yang berbunyi "SumSel Maju Untuk Semua" dari kata tersebut terdapat banyak makna yakni salah satunya pasangan tersebut menginginkan Sumatera Selatan menjadi provinsi yang maju dan unggul guna untuk mensejahterakan rakyatnya. Di dalam misinya merangkum dengan sangat jelas apa saja yang dibutuhkan oleh seluruh lapisan masyarakat baik dikota maupun perdesaan. Dalam misi kerja Herman Deru-Mawardi Yahya terdapat 5 misi yaitu : Pertama, membangun Sumsel berbasis ekonomi kerakyatan yang didukung sektor pertaniaan, industri dan UMKM yang tangguh untuk mengatasi pengangguran dan kemiskinan baik diperkotaan maupun perdesaan. Kedua, meningkatkan kualitas Sumber Daya Manusia (SDM), baik laki-laki maupun perempuan, yang sehat, berpendidikan, professional dan menjunjung tinggi nilainilai keimanan, ketaqwaan, kejujuran dan integritas. Ketiga, mewujudkan tata kelola pemerintahan yang bebas korupsi, kolus dan nepotisme dengan mengedepankan, transparansi dan akuntabelitas yang didukung aparatur pemerintah yang jujur, berintegritas, professional, dan responsif. Keempat, membangun dan meningkatkan kualitas dan kuantitas infrastruktur, termasuk infrastruktur dasar guna percepatan pembangunan wilayah pedalaman dan perbatasan untuk memperlancar arus barang dan mobilitas penduduk, serta mewujudkan daya saing daerah dengan mempertimbangkan

\footnotetext{
${ }^{9}$ Philip Kotler dan Gery Amstrong, Prinsip-prinsip Pemasaran, (Jakarta, Erlangga: 2006), h. 61.
} 
pemerataan dan keseimbangan daerah.Kelima, meningkatkan kehidupan beragama seni dan budaya, olahraga dan pariwisata.

\section{Promosi Politik}

Promosi adalah suatu aktivitas komunikasi yang dilakukan oleh seorang atau suatu perusahaan dengan masyarakat luas, dimana tujuannya adalah untuk memperkenalkan sesuatu (barang/jasa/merek/perusahaan) kepada masyarakat dan sekaligus mempengaruhi masyarakat luas agar membeli dan menggunakan produk tersebut. Begitu pula promosi dalam politik adalah aktivitas komunikasi baik secara langsung maupun tidak langsung yang dilakukan untuk mendapat suara pemilih terbanyak.

Promosi yang dilakukan oleh tim sahabat HDMY ini khususnya lebih tertuju pada kalangan milenial Kota Palembang. Mengingat bahwa Kota Palembang adalah Ibukota dari Sumatera Selatan yang rata-rata penduduknya adalah kaum kekinian atau lebih banyak mengenal teknologi. Dari sinilah tim sahabat HDMY berusaha mengiring opini publik untuk memberikan dukungan dan suaranya kepada pasangan Herman Deru-Mawardi Yahya menyasar kepada penduduk Kota Palembang melalui media sosial. Lebih utamanya lagi tim sahabat HDMY tersebut berusaha menarik suara dari kalangan remaja atau kaum milenial yang kebanyakan adalah pengguna dari media sosial secara aktif. ${ }^{10}$

\section{Harga}

Harga dalam marketing politik mencakup banyak hal, mulai ekonomi, psikologis sampai ke citra nasional. ${ }^{11}$ Kampanye politik memang harus bisa menyentuh segenap lapisan masyarakat. Hal ini bisa dicapai dengan melakukan segmentasi publik.Sebuah institusi politik harus bisa mengidentifikasi dan memetakan struktur serta karakteristik masyarakat. Pemetaan ini bisa dilakukan secara geografis. Identifikasi dilakukan dengan melihat konsentrasi penduduk disuatu wilayah, penyebaraannya dan kondisi fisik geografisnya. Pemetaan juga bisa dilakukan secara demografis, di mana pemilih dikelompokkan berdasarkan tingkat pendidikan, pekerjaan, usia, kelas sosial, pemahaman akan dunia politik, kepercayaan agama, dan etnis. Pemetaan juga perlu dilakukan berdasarkan keberpihakan pemilih, misalnya saja berapa pendukung tradisional, berapa pendukung partai atau kandidat lain, berapa jumlah massa mengambang (floating mass) dan mungkin juga berapa persentase golput.

Kampanye sendiri merupakan wujud dari pendidikan politik masyarakat yang dilaksanakan secara bertanggung jawab dengan maksud untuk meningkatkan partisipasi pemilih dalam kampanye meliputi, jujur, terbuka dan dialogis. Melalui kampanye dialogis, komunikasi dengan rakyat akan tercipta dua arah. Calon pemimpin bisa menyerap apa yang jadi aspirasi rakyatnya. Rakyat bisa mendapat ruang untuk bicara. Kampanye dialogis akan mendorong pendewasaan politik publik. Setidaknya calon pemimpin akan mengetahui lebih jauh tentang apa yang menjadi

\footnotetext{
${ }^{10}$ Muhaimin, A., \& Shammania, S. (2018). Citra Perempuan Pada Produk Rokok di Era Tahun 1930-1950. Jurnal Studi Sosial Dan Politik, 2(2), 122-135. https://doi.org/https://doi.org/10.19109/jssp.v2i2.4057

${ }^{11}$ Niffenegger dalam Firmanzah, Marketing Politik: Antara Pemahaman dan Realitas (Jakarta, Yayasan Obor Indonesia, 2012), h.205
} 
kebutuhan dan aspirasi rakyatnya. Sebaliknya rakyat atau konstituen akan mengenal lebih dekat sosok calon pemimpin.

\section{Kesimpulan}

Pertarungan untuk menjadi pemimipin di Sumatera Selatan telah usai digelar. Terpilihlah pasangan Herman Deru-Mawardi Yahya yang akan menjadi pemimpin Sumatera Selatan selama 5 tahun kedepan. Pasangan ini berhasil keluar dan memenagi pertarungan Pilgub ini dengan meraih perolehan suara tertinggi dan mengalahkan para pesaingnya. Dari hasil penelitian yang ditemukan oleh peneliti dilapangan terdapat beberapa poin dari proses marketing yang dilakukan oleh tim sukses Herman Deru-Mawardi Yahya di Kota Palembang.

Kegiatan marketing politik yang dilakukan oleh tim sukses Herman Deru-Mawardi Yahya di Kota Palembang menggunakan beberapa proses marketing politik yaitu dengan konsep 4P, produk politik, promosi, harga (price) dan tempat (place). Upaya pengenalan atau penyebaran produk politik kepada kalangan pemilih, dengan memperkenalkan pasangan Herman DeruMawardi Yahya melalui produk (program kerja atau visi misi) yang ditawarkan oleh pasangan tersebut maka akan membuat masyarakat pemilih menjadi yakin dengan apa yang akan dikerjakan oleh pasangan ini kedepannya jika menang nantinya. Penyebaran produk politik ini ditujukan agar masyarakat menjadi yakin dengan pasangan tersebut dan juga memperlihatkan kinerja pasangan tersebut dalam masa pimpinannya terdahulu didaerah jabatan masing-masing.

Promosi yang dilakukan oleh tim sukses Herman Deru-Mawardi Yahya di Kota Palembang dilakukan dengan berbagai cara, seperti menggunakan spanduk/baliho, menggunakan media massa, media elektronik dan melalui media sosial, ini dilakukan agar seluruh lapisan masyarakat bisa mengetahui siapa sosok sebenarnya dari pasangan tersebut dan apa program kerja yang akan dilakukan nantinya.

Harga atau upaya pendanaan dalam kampanye yang dilakukan oleh tim sukses Herman Deru-Mawardi Yahya ini didapat dari partai dan dari pasangan Herman Deru-Mawardi Yahya, adapun harga image yang dibangun oleh tim sukses Herman Deru-Mawardi Yahya di Kota Palembang dengan memperlihatkan kembali rekam jejak pak Deru dalam memimpin Kabupaten OKU Timur selama 2 periode dan juga pak Mawardi dalam masa jabatannya sebagai Bupati di Kabupaten Ogan Ilir (OI). Tempat, tidak ada tempat khusus yang ditargetkan untuk berkampanye oleh tim sukses Herman Deru-Mawardi Yahya di Kota Palemabang, karena memang tim sukses di Kota Palembang tidak melakukan kampanye akbar. Namun, meskipun tak melakukan kampanye akbar Bapak Herman Deru pernah melakukan kampanye dialogis dengan warga Kota Palembang. Tim sukses Herman Deru-Mawardi Yahya di Kota Palembang menggerakan seluruh lapisan pendukungnya untuk mengkampanyekan pasangan ini di seluruh sudut Kota Palembang terutama dikawasan yang banyak dikunjingi oleh masyarakat Kota Palembang.

Kemenangan yang dicapai oleh pasangan Herman Deru-Mawardi Yahya bukanlah suatu yang mudah digapai.Mengingat pada tahun 2013 Herman Deru juga pernah ikut dalam pencalonan sebagai calon gubernur Sumatera Selatan namun gagal. Seolah belajar dari kesalahan dan kegagalan bapak Herman Deru sangat gencar melakukan kampanye disetiap Kota/Kabupaten yang ada di Sumatera Selatan baik itu dalam bentuk kampanye akbar maupun kampanye dialogis. 


\section{DAFTAR PUSTAKA}

Apriani, R., \& Maharani, M. (2019). Strategi Pemenangan Pasangan Calon Herman Deru Dan Mawardi Yahya Pada Pilkada Sumatera Selatan Tahun 2018. Jurnal Studi Sosial Dan Politik, 3(1), 17-27. https://doi.org/https://doi.org/10.19109/jssp.v3i1.4065

Aziz Nyimas, Peran Marketing Dalam Dunia Politik, Yayasan Obor Indonesia, April 2007, $x x i+357 \mathrm{hlm}$.

Chandra, A., Darmawan, E., \& Yesi, Y. (2018). Upaya Komisi Pemilihan Umum Provinsi Sumatera Selatan dalam Meningkatkan Partisipasi Pemilih pada Pilkada Serentak 2018 dan Pemilu Serentak 2019. Jurnal Studi Sosial Dan Politik, 2(1), 12-30. https://doi.org/https://doi.org/10.19109/jssp.v2i1.4061

Firmanzah, Marketing Politik: Antara Pemahaman dan Realitas (Jakarta, Yayasan Obor Indonesia, 2012

Firmanzah, Mengelola Partai Politik:Komunikasi dan Positioning Ideologi Politikdi Era Demokrasi, (Jakarta, Yayasan Obor Indonesia: 2007)

Muhaimin, A., \& Shammania, S. (2018). Citra Perempuan Pada Produk Rokok di Era Tahun 19301950. Jurnal Studi Sosial Dan Politik, 2(2), 122-135. https://doi.org/https://doi.org/10.19109/jssp.v2i2.4057

Niffenegger dalam Firmanzah, Marketing Politik: Antara Pemahaman dan Realitas (Jakarta, Yayasan Obor Indonesia, 2012), h.205

Philip Kotler dan Gery Amstrong, Prinsip-prinsip Pemasaran, (Jakarta, Erlangga: 2006)

Syukri, A., \& Meilandi, R. (\&nbsp;). Strategi Partai Koalisi dalam Pemenangan AW Nofiadi Mawardi - Ilyas Panji Alam pada Pemilihan Kepala Daerah Kabupaten Ogan Ilir Tahun 2015. Jurnal Studi Sosial Dan Politik, 2(1), 31-43. https://doi.org/https://doi.org/10.19109/jssp.v2i1.4062 